\title{
A framework and tool to manage Cloud Computing service quality
}

\author{
Francisco José Domínguez-Mayo • Julián Alberto García-García • María José \\ Escalona • Manuel Mejías • Matias Urbieta • Gustavo Rossi
}

\begin{abstract}
Cloud Computing has generated considerable interest in both companies specialized in Information and Communication Technology and business context in general. The Sourcing Capability Maturity Model for service (e-SCM) is a capability model for offshore outsourcing services between clients and providers that offers appropriate strategies to enhance Cloud Computing implementation. It intends to achieve the required quality of service and develop an effective working relationship between clients and providers. Moreover, quality evaluation framework is a framework to control the quality of any product and/or process. It offers a tool support that can generate software artifacts to manage any type of product and service efficiently and effectively. Thus, the aim of this paper was to make this framework and tool support available to manage Cloud Computing service quality between clients and providers by means of e-SCM.
\end{abstract}

Keywords Quality management - Software quality - SQA · Quality concepts · Offshore outsourcing · Cloud Computing

F. J. Domínguez-Mayo $(\bowtie)$ · J. A. García-García · M. J. Escalona · M. Mejías Department of Computer Languages and System, University of Seville, Seville, Spain e-mail: fjdominguez@us.es

J. A. García-García

e-mail: julian.garcia@iwt2.org

M. J. Escalona

e-mail: mjescalona@us.es

M. Mejías

e-mail: risoto@us.es

M. Urbieta - G. Rossi

LIFIA, Facultad de Informática, UNLP, La Plata, Argentina

e-mail: murbieta@lifia.info.unlp.edu.ar

G. Rossi

e-mail: gustavo@lifia.info.unlp.edu.ar 


\section{Introduction}

Cloud Computing is a paradigm that stores information permanently on Internet servers and sends it temporally to clients' caches (e.g., desktops, entertainment centers or laptops) (Monaco 2012). Cloud Computing is a new business services and technology model, which allows the user to access a catalogue of standardized services and meet business needs, paying only for consumption made. It is flexible and adaptive, particularly if demands are not predictable or in case of peak workloads.

This new paradigm allows the number of network-based services to increase. This fact benefits suppliers that can offer, quickly and efficiently, a larger number of services to users who are able to access them, enjoying the "transparency" and immediacy of the system as well as the pay per use.

In fact, offshore outsourcing and Cloud Computing perfectly blend tradition and innovation. Besides, most information and communication technology (ICT) providers have included offerings in their Clouds, as an alternative in the set of solutions with the aim of adapting traditional concepts to the capabilities offered by the Cloud.

Cloud Computing (Wei 2010), possibly the most significant new technique in the twenty-first century, is now having great impact on society, especially on the business world. It provides services that release clients from worrying about data processing problems so that they can focus on their major businesses. It is a concept that incorporates software as a service, such as Web 2.0 and other recent concepts, also known as technological trends. All of them rely on the Internet to meet the user's computing needs. Cloud Computing (Ma 2012) can supply critical services for business management, reducing ICT costs and maintenance costs of hardware and software effectively. In the meanwhile, it can enable enterprises to access professional ICT solutions with less ICT investment. Cloud Computing is highly relevant to a country's ICT industry, as it provides organizations with substantial benefits, including increased agility, although it would also entail considerable risks. Cloud Computing technology is a major trend with implications in ICT organizations. A growing number of providers are starting to supply Cloud Computing with offerings, and analysts predict that some enterprises will purchase a significant percentage of their applications and infrastructure as Cloud Computing service in the near future.

The new developments in the IT field offer enjoyment, comfort and convenience (Wei 2010). Cloud Computing is one of the latest developments in the ICT industry, also known as on-demand computing. It provides full scalability, reliability, high performance and a relatively low-cost feasible solution as compared to dedicated infrastructures. It is a service-shaped application delivered on the Internet and system hardware at data centers offering these services. This technology is designed to admit a common collection of resources on request. It is proving extremely striking to cash-strapped IT departments that are requested to deliver better services under pressure.

According to ITSqc (ITSqc Official site 2012) (a spin-off from Carnegie Mellon University), organizations are increasingly delegating IT-intensive business activities as Cloud Computing service to service providers, taking advantage of new capabilities in the global telecommunications infrastructure. Service providers range from in-house units to sharedservice centers to capture offshore units to external service providers. Business processes being delegated range from in-sourced shared services to outsourced routine and noncritical tasks, as well as outsourced strategic processes that have direct impact on revenues. Managing and meeting clients' expectations and giving effective governance of these relationships are major challenges in these business relationships. eSourcing Capability Models (e-SCM) are "best practices" capability models supported by a set of qualification 
methods to improve the Internet-enabled economy with sourcing relationships. Both the eSourcing Capability Model for service providers (e-SCM-SP) and the eSourcing Capability Model for client Organizations (e-SCM-CL) are complementary models addressing both sides of these relationships.

The main goal of this research is to lay the basis for a framework and a tool support to manage Cloud Computing quality by means of e-SCM capability model. The paper is organized into the following sections. Section 2 introduces a global analysis of the situation. Section 3 describes e-SCM capability models for Clients and providers. Section 4 analyzes the framework that will let us manage Cloud Computing and offshore outsourcing quality. In Sect. 5, both the factory and the tool support that is generated in terms of e-SCM models are presented. Finally, Sect. 6 states a set of conclusions, contributions and possible future work.

\section{Related work}

We have carried out a systematic literature review (SLR), which has helped us study the most important work on the same topic, before tackling the problem pointed out in this paper. Moreover, there are other reasons regarding this study for undertaking a SLR, such as identifying gaps in offshore outsourcing and Cloud Computing quality management in order to suggest areas for further investigation and offer a background to appropriately position new research activities related to them. Specifically, we aim to determine the most analyzed offshore outsourcing and Cloud Computing studies to assess whether a framework and a tool support exist to manage offshore outsourcing and Cloud Computing quality, which can reduce costs, effort and time.

In addition, this SLR also intends to capture information and observe trends and technology on the increase from the outside in order to select, analyze, disseminate and communicate them. The objective is to turn them into knowledge to make less risky decisions and be able to anticipate changes. Managing offshore outsourcing and Cloud Computing quality has some benefits such as setting direction and meeting customers' expectations, improving process control, reducing wastage, lowering cost, increasing market share, facilitating training, involving staff and raising morale, among others.

The review method is based on Kitchenham's research protocol (Kitchenham and Charters 2007). This section defines the search strategy as well as the sources used, the studies selection and the selection execution.

\subsection{Sources selection}

This section compiles the sources to look for primary studies. First of all, we carried out preliminary searches to identify existing systematic reviews and assess the volume of potentially relevant studies, so that in this case, we found the following relevant initiatives: Brinkkemper and Jansen (2012), Samimi and Patel (2011), Timmermans et al. (2010), Yang and Tate (2009), Hughes (2011), Buyya et al. (2009), Alvi et al. (2011), Hu et al. (2011); Roberts II and Al-Hamdani (2011), Dudin and Smetanin (2011), Song and Su (2011), Marta et al. (2011), Haider and Wahab (2011), Lian-xiang (2011), Nazareno et al. (2010), and Rebollo et al. (2012).

After that, a Web search was performed to find out other relevant new concepts associated with our domain. For this purpose, we used several sets of keywords by combining the main concepts/terms of our study. Some examples are as follows: 
- "offshore outsourcing" AND "cloud computing"

- "offshore outsourcing" AND "quality"

- "offshore outsourcing" AND "evaluation"

- "cloud computing" AND "quality"

- "cloud computing" AND "evaluation"

The last step consisted in looking for references of papers in previous reviews in order to identify more concepts.

\subsection{Studies selection}

The selection criteria to evaluate study sources were as follows: the availability for consulting articles on the Internet or on the digital library of the University of Seville, which has e-books and also access to other resources such as Google Scholar, Scopus, Mendeley, Science Direct, ISI Web of Knowledge, ACM Digital Library, CiteSeerX or the IEEE digital library, among others.

- Search Type 1: As there are many work published, our search started gathering those papers that only included concepts in the Title, excluding those issued prior to 2006. Then, we analyzed results and studies dealing with managing offshore outsourcing and Cloud Computing quality. If the paper topic was not related to these topics, then it was excluded of the study. The process to consider a paper was as follows: First, we reflected on Title, Abstract, Keywords and Content and finally on Conclusions. Most papers were included in this type of search, since the concept word in the Title reveals that the paper focuses on that concept.

- Search Type 2: Later, we searched through the concepts included in the Abstract, Keyword and Title, excluding again those papers issued prior to 2006. Nevertheless, the large number of papers found by search engines constituted a relevant figure of interest. Due to such unexpected figure, it was not practicable to read all papers in depth.

- Search Type 3: Finally, we searched through the concepts in all fields. Similar to Search Type 2, we were only interested in finding whether a framework or tool support to manage offshore outsourcing and Cloud Computing quality existed or not.

\subsection{Selection execution}

In this section, we present the studies found after executing our SLR. As far as maturity models are concerned, TickITplus (2012) defines five levels of maturity in an organization, in accordance with the requirements stated in ISO/IEC 15504-2. These levels are, in ascending order, Foundation, Bronze, Silver, Gold and Platinum. Levels from Bronze to Platinum are progressed by determining whether an organization has complied with certain process attributes by means of capability assessments. Compliance at the Foundation level is determined by making sure that an organization has identified processes correctly and is operating them. It is recognized that existing TickIT organizations aim to move on to the graded levels at their own pace and as improvements allow. Consequently, the Foundation level enables organizations to advance to TickITplus with minimal effort and then to start with their maturity journey process.

The scheme is designed to permit combinations of IT-related requirements and reference standards in order to be mapped into BPL, which will initially include ISO 9001. As 
the scheme develops, further requirements and reference standards could be added ondemand, such as:

- ISO/IEC 20000-1, Information technology-Service management-Part 1: Service management system requirements

- ISO/IEC 27001, Information technology-Security techniques-Information security management systems-Requirements

- ISO/IEC 25030, Software engineering-Software product Quality Requirements and Evaluation (SQuaRE)—Quality requirements

- IEC 61508, Functional safety of electrical/electronic/programmable electronic safetyrelated systems.

- ISO 22301:2012, Societal security-Business continuity management systemsRequirements

In these lines, Capability Maturity Model Integration (CMMI) (CMMI Official site 2012) is a process improvement approach whose goal is to help organizations better their performance. CMMI can be used to guide process improvement across a project, a division or an entire organization. CMMI Version 1.3 is currently supported. CMMI helps integrate traditionally separate organizational functions, set process improvement goals and priorities, provide guidance for quality processes and offer a point of reference for appraising current processes.

ITSqc (ITSqc Official site 2012) has released a technical report series that compares in detail e-SCM-SP with other standards, good practices and frameworks, including Software CMM, People CMM, CMMI, ISO 9001, BS 15000 and ITIL (ITIL Official site 2012), COBIT and COPC. These comparisons show clearly the value-added differences of e-SCM-SP and the complementary relationships it keeps with other quality models. Due to the experiences from more than 40 appraisals on multiple continents, it shows that organizations that already are implementing one or more of these frameworks, using an internal progression capability, are well positioned to successfully improve e-SCM-SP.

ISO is a worldwide federation of national standards bodies (ISO member bodies). International standards are issued thanks to the collaborative work carried out by ISO technical committees with international organizations, governmental and non-governmental bodies. ISOs most recent family of standards for quality management systems are currently in their final draft (FDIS) form and comprise:

- ISO/FDIS 9000:2000—Quality management systems-Fundamentals and vocabulary

- ISO/FDIS 9001:2000_Quality management systems—Requirements

- ISO/FDIS 9004:2000—Guidelines for performance improvement

They are built around business processes with a strong emphasis on improvement and a focus on meeting customers' needs. The new standards originated from a regular 6-year review and are intended to be generic and adaptable to all kinds of organizations. ISO 9002 and ISO 9003 are discontinued (but they can still be used by those organizations authorized against them during the 3-year transition period), whereas ISO 9001 and ISO 9004 are designed to apply together, although they can be used independently. ISO Series can constitute the means by which a holistic management system can be implemented, by integrating quality, health, safety and environmental responsibility, with the audits carried out either separately or as a whole. Now ISO standard is also more closely aligned with the requirements of the EFQM Excellence Model.

In contrast, Brinkkemper and Jansen (2012) provide ICT practitioners with more insight into offshore outsourcing. This book assists in several parts of the outsourcing process: 
firstly, finding and establishing offshore outsourcing relationships; secondly, maintaining and managing such relationships; and, finally, governing the outsourcing projects successfully.

As far as works about Cloud Computing are concerned, Samimi and Patel (2011) provide a comparative review grid on Cloud Computing economic and pricing models, from which appropriate fees and charging models can be chosen to meet particular business objectives. The actual choice depends on many other factors like enterprise regulations, tax laws, service-level agreements and return on investments, which are relevant, but outside the scope of this paper. The authors suggest the basic core principles and a comparative review of the latest and most appropriate economic and pricing models applicable to grid and Cloud Computing in order to propose better models for the future.

In Buyya et al. (2009), the authors conclude that there is a limited support for marketoriented resource management and a need to be extended to support negotiation of QoS between clients and providers to establish SLAs, and mechanisms and algorithms for VM resources allocations to meet SLAs, and to manage risks associated with the violation of SLAs. Furthermore, interaction protocols need to be extended in order to assist interoperability between different Cloud service providers.

In Timmermans et al. (2010), the authors identify ethical issues of Cloud Computing that arise from the fundamental nature of the technology rather than from any specific circumstances. Authors describe how these general features were identified and how ethical issues arising from them were collected, and conclude by discussing means of addressing them.

Zhao (2010) illustrates with several examples Cloud Computing as possibly the most significant new technique in the twenty-first century that is now bringing enormous impact on society, especially on the business world. It provides services that release clients from worrying about data processing problems, so that they can focus on their major businesses. The author shows how Cloud Computing will make the business world simpler, more efficient and specialized.

In addition, Yang and Tate (2009) present a descriptive literature review and a classification scheme for Cloud Computing research. The former consists of 58 articles published since the recent inception of Cloud Computing. Authors classify articles and present results in a scheme structured into four main categories: technological issues, business issues, applications and general. The results confirm that although current Cloud Computing research is still skewed toward technological issues, such as performance, network and data management, new research topic regarding the social and organizational implications of Cloud Computing is emerging.

Finally, Hughes et al. (2011) synopsize previous investigatory research concerning these emerging problems. They then continue describing and reviewing the structure and operation of the Cloud Computing Management System which applies an object-mapping declarative language that, in turn, utilizes an object-oriented system to support operations.

We hope this review will provide a snapshot and a reference source of the current state of Cloud Computing research and stimulate further research interest.

\section{Cloud Computing and e-SCM}

The result of the SLR shows no found work about frameworks and tool support that ensures management and quality continuous improvement in Cloud Computing between clients and providers. 
There is no doubt that Cloud Computing is a key factor that will accelerate the processing of application maps and models of ICT infrastructure management, which has been performed until now by organizations. Adopting the concept of Cloud provides significant benefits such as, total scalability of the business, reduction ICT investment and operational costs, use of flexible capacity in times when the business is demanded, possibility of introducing new economic models of pay per use, improvement of connectivity business with customers at anytime or anywhere, and more speed when launching new products and services demanded by the business, among others.

The advent of Cloud Computing has caused a stir both in specialized ICT companies and companies in general. All are willing to gamble on the opportunities and benefits generated by the Cloud, although there is still some confusion, especially when trying to define and know what exactly the differences between services that have already been offering for years are. Offshore outsourcing is precisely one of the segments where there is more confusion, especially among organizations that aim to outsource part of their business. On the one hand, offshore outsourcing allows a third party to provide services more efficiently based on specialization and economies of scale. On the other hand, Cloud Computing to outsource infrastructure and management software is seemed as an advantage to customers because (1) they only pay for the resources they need, without investment on the platform or over sizing it, (2) what is needed can be provisioned with flexibility and immediacy without long purchasing processes and guaranteed levels of safety and quality of service.

Most ICT organizations have decided to include Cloud Computing within their offerings, especially as an alternative in the set of solutions, by adapting traditional concepts to the capabilities offered by new technologies and the Cloud model, in order to meet any organization's needs.

Cloud Computing is an option that complements the existing range of different models of implementation and consumption of services. The scope of offshore outsourcing on organizations has offered in the market for years, joined to this new concept of service, the pay-per-use model provides companies with the possibility to ensure the transfer of certain services/applications or environments to a platform outside their facilities and organizational structure.

Cloud Computing can encompass a variety of infrastructures and services within information technology. Three main categories of external service that fall within our broad Cloud Computing definition are identified in Vats et al. (2012) as Software as a Service (SaaS), Platform as a Service (PaaS) and Infrastructure as a Service (IaaS)

Client companies need to ensure that the outsourcing company can offer services of the required quality when selecting a partner for offshore outsourcing, and an effective working relationship can be developed with the outsourcing company. Clients need to be assured that outsourcers provide an agreed-level quality of work. Initially, this not always happens with offshoring.

Various quality models and standards are introduced to overcome this problem. These include e-SCM, which recognizes that both service provider and client need to work together to ensure success. Carnegie Mellon University led a consortium in 2001 to develop the eSourcing Capability Maturity Model for service providers (e-SCM SP), covering a wider range of functions than CMMI.

According to ITSqc (we have presented this study in Sect. 2), there are two basic uses of e-SCMs, implementation and appraisal. A formal method to determine which parts of the model an organization implements (and do not implement) is the appraisal usage. E-SCM appraisal method is called e-SCM Capability Determination Method. This method is the 
same for both models. It copes with completing questionnaires, reviewing documentation, conducting interviews with site personnel and compiling and reporting results. ITSqc trains and authorizes teams of Authorized Evaluators to conduct Capability Determinations.

E-SCMs can also be used as a guide to sourcing-related process implementation. E-SCMs are partial requirements specifications for a process. They are not directly implementable processes. The general approach followed when using e-SCM models for improvement purposes first deals with determining the gaps between the organization's current processes and the applicable model practices, then building a plan for process implementation and later managing the implementation steps described in the plan to completion. Finally, the process is repeated (gap analysis, plan and implementation).

The eSourcing Capability Model for service providers (e-SCM-SP) (ITSqc Official site 2012) helps sourcing organizations manage and reduce their risks and improve their capabilities along the entire sourcing lifecycle. The model practices can be conceived as the best practices associated with successful sourcing relationships. It addresses the critical issues related to IT-enabled sourcing (eSourcing) for both outsourced and in-sourced (shared services) agreements.

Service providers use the e-SCM-SP and its accompanying Capability Determination methods to evaluate their eSourcing capabilities and become e-SCM-SP certified. This status poses an advantage over their competitors. The main objectives of e-SCM SP (service providers) are as follows:

- Improving service provider's capability along the sourcing lifecycle by providing them with guidance.

- Giving clients service providers' capability by evaluating them.

- Supplying service providers with a standard to differentiate themselves from their competitors.

- Offering a process framework for the formation and management of enduring outsourcing relationships between service providers and clients. It is specifically developed to meet IT and process management outsourcing challenges.

Next, we present a summary of e-SCM SP levels:

- Level 1:

- The organization lacks proper management practices with improper procedures and unformulated systems.

- The organization has no particular performance measurement activities or procedures.

- Projects meet frequent crises, and as a consequence, they also exceed their budget and time schedules.

\section{- Level 2:}

- Capturing and understanding the client's requirements and then designing and deploying the service to meet these requirements.

- Delivering the necessary services at agreed service levels and managing all the risk.

- Providing proper training or acquiring personnel with expertise in the demanded skills and also maintaining the up-to-date technology as well as the required infrastructure for this contract. 
- Keeping a proper service in order to collect and disseminate the information to control and track service delivery.

\section{- Level 3:}

- More maturity with respect to market sector targets, cultural attributes and capability to keep activities under control and measure.

- Activities obtained from previous experience, sharing the knowledge gained from their previous phases' engagements and documentation.

- Capability to monitor and control infrastructure and be able to reward personnel performance.

- Forecasting and preventing the risk involved during the relationship and the project development.

\section{- Level 4:}

- Customizing their services with respect to different sectors of client's projects.

- Predicting their performance regarding their previous successful case studies and proactively improve performance.

- Encouraging innovation and benchmarking the organizational performance.

- Incorporating the appropriate technology advances by performing systematic evaluation.

- Level 5:

- The supplier has attained complete maturity.

- The supplier will be rewarded for sustaining enhancement over a period of time.

- The supplier requires level 4 performances during certification evaluations.

In e-SCM SP model, practices are defined for each organizational element, which in turn contains Overall Practices and Phase-Specific Practices (Pre-Contract, Contract Execution and Post-Contract). The main elements that are involved in IT service and IT solution organizations are as follows: Organizational Management, People Management, Business Operations, Technology and Knowledge Management.

In addition, the eSourcing Capability Model for client Organizations (e-SCM-CL) addresses a full range of client organization tasks, ranging from developing the organization's sourcing strategy, planning for sourcing and service provider selection or initiating an agreement with service providers to managing service delivery to completing the agreement. The main objectives of e-SCM CL are as follows:

- Providing guidance to the client organization that will improve its capability across the sourcing areas.

- Offering client organizations an objective means of evaluating their sourcing capability.

- Helping client organizations efficiently manage their service providers and reduce their deficiencies in performance.

Next, we present a summary of the e-SCM CL levels:

\section{- Level 1 Performance Sourcing:}

- The client organization has not fully implemented the best practices stated in level 2 . 
- There is a high chance that the outsourcing relationship will fail.

- Level 2 Consistently managing sourcing:

- The client organization has fully implemented the capability level 2 practices.

- They can manage the sourcing activities and get executive support.

- Level 3 Managing organizational sourcing performance:

- Client organizations can manage their sourcing activities according to their strategy.

- They have to implement all level 2 practices along with level 3 practices to achieve this level.

- Level 4 Proactively enhancing value:

- The client concentrates on enhancing their performance across the sourcing relationship and also uses innovations to achieve objectives.

- Apart from capability level 2 and 3 practices, more practices have to be implemented for this level.

- Level 5 Sustaining Excellence:

- Clients demonstrate measurable, sustained and consistent performance by effectively implementing all level 2, 3 and 4 practices.

- No additional practices are required at this level.

\section{Managing Cloud Computing quality between clients and providers}

Clients and providers have to align their capabilities in order to ensure a high-level Cloud Computing service quality. As shown in Fig. 1, the common capability they share is obtained after analyzing their capabilities separately by means of checklists containing all properties established in a Quality Model. Our checklists identify what phase and capability implement clients and providers. The figure below represents the results of the analysis process. As a consequence, this process outlines how both clients and providers are aligned.

Two quality models must be defined to achieve our goal: one for clients and other for providers. In Sect. 4.1, we define quality model metamodels to describe these models. Section 4.2 shows the application of this metamodel to e-SCM CL and e-SCM SP, and finally, in Sect. 4.3, we propose the framework to manage Cloud Computing service quality using both quality models.

\subsection{The quality model}

The Quality Model (Domínguez-Mayo et al. 2012a) represents the core, and quality management revolves around it. We propose a Quality Model metamodel consisting in a simplification and adaptation of ISO/IEC 15939 (ISO/IEC 15939:2007 2012) so that the model instantiation can be more flexible and practical. The main objective concludes that quality management becomes strategically active. Therefore, all the strategic assets have to be identified, and it is necessary to capture, define and validate the Quality Model that will 


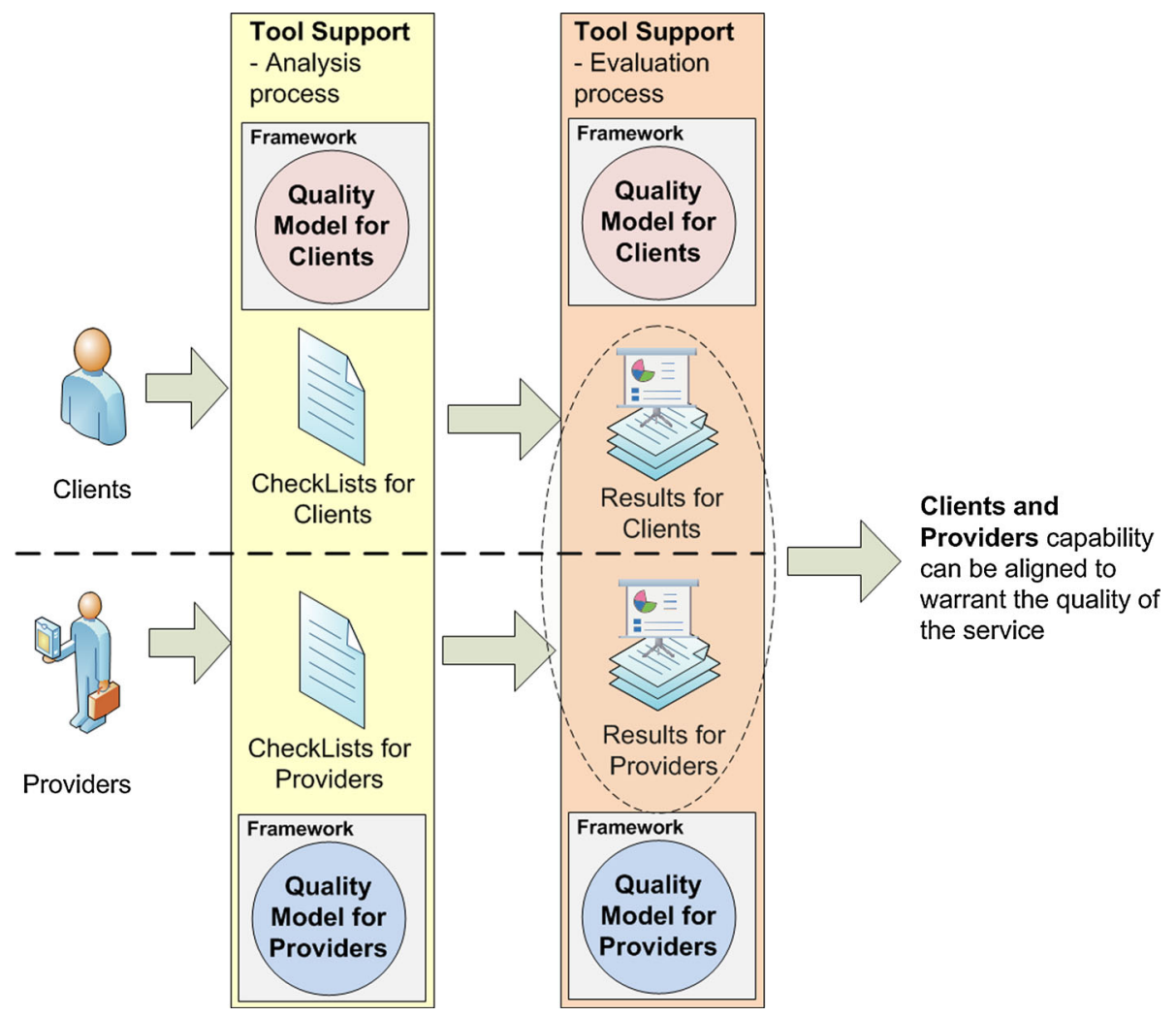

Fig. 1 A proposed framework to manage Cloud Computing quality services between clients and providers

be used for quality management. The Quality Model contains Features and Sub-Features (both are categories of an entity's properties). A Feature is a higher-level category of the domain description of an entity, while a Sub-Feature is a lower-level category. A Property points out the degree to which a Sub-Feature is measured, that means that a Property is used for measuring Sub-Features.

Below, different levels for Properties and Quality Characteristics are explained (Fig. 2).

- Feature (FT- $<$ Level $1>$ ): It is a general concept of an entity, a set of properties, but a higher-level concept of an entity's characterization that describes it broadly. A Feature has a set of Sub-Features.

- Sub-Feature (FT- $<$ Level $0>$ ): It is a specific concept of an entity. It is a set of Properties, but a lower-level concept of an entity's characterization. It is used to categorize the Properties of the entity in two levels (Feature and Sub-Feature).

- Property: It indicates the degree to which a Sub-Feature is measured. Particularly, a Property is used for describing and analyzing the Sub-Features of an entity. In terms of Properties, our aim is to look for a series of qualitative and quantitative Properties based on their nature, although it might be interesting to have standard properties on Cloud Computing that are, somehow, centralized. In the literature, numerous references to metrics can be found, but standardization has yet to be carried out. 


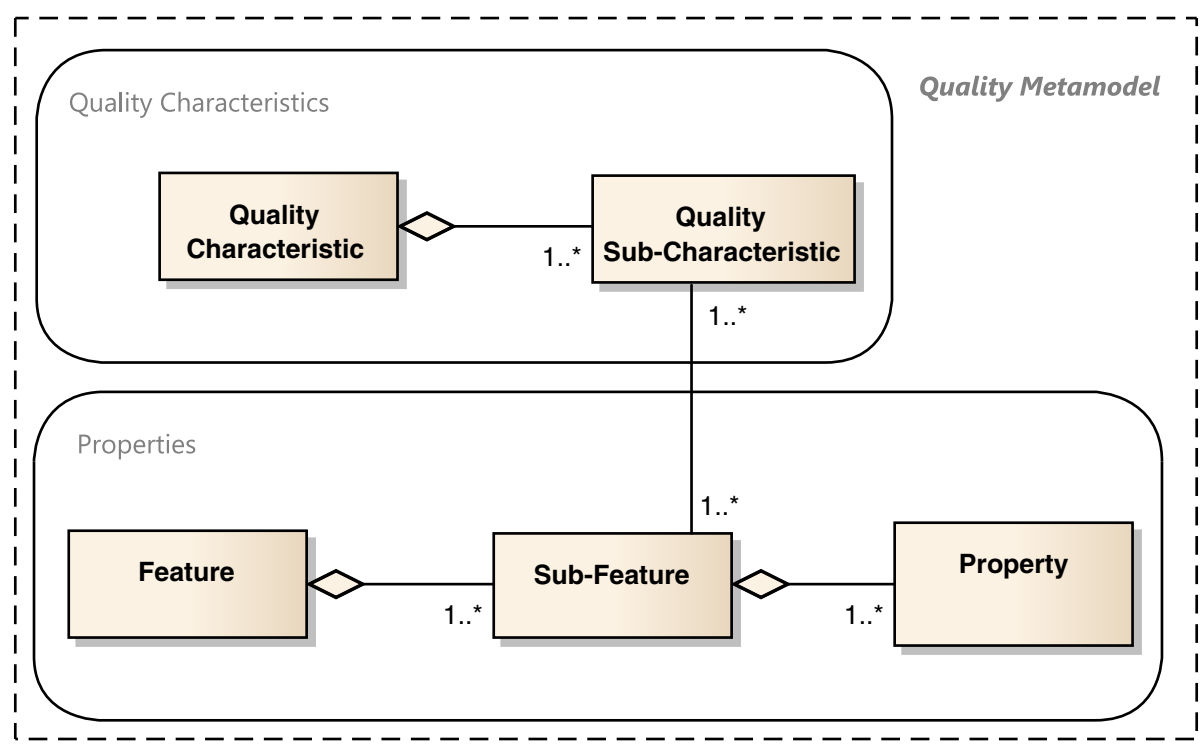

Fig. 2 Quality metamodel

As explained before, Quality Characteristics hierarchical by Quality Characteristics (or QC- $<$ Level 1 $>$ ) and Quality Sub-Characteristics (or QC- $<$ Level 0 $>$ ) are quality aspects that together with Properties have to be assured on an entity.

Subsequently, Fig. 1 shows that the author would define the relations between Properties and Quality Characteristics to identify how each Sub-Feature is influenced in each Quality Sub-Characteristic. These association links would represent dependencies between Properties and Quality Characteristics. They would illustrate Quality Characteristics that are affected by Sub-Features or areas of the entity that would be significantly affected, if changed.

Association links may be based on proven and real-world experience. The impact of each Sub-Feature on Quality Sub-Characteristics must be demonstrated, and a real-case study applied to a number of real projects must determine requirements. This should be supplemented by references to published literature. Therefore, a weight is used to define the importance of a Property in a Sub-Feature value.

- Properties are the descriptive environment where quality management is going to be performed.

- Quality Characteristics are those quality aspects designers must ensure in the set of Properties that are offered to users.

On the contrary, Quality Characteristics and Quality Sub-Characteristics are quality aspects influenced by an environment description or Properties. In other words, Quality Characteristic is a higher-level quality aspect. Higher-level attributes are called Quality Characteristics, and lower-level attributes are called Quality Sub-Characteristics, in a hierarchy of Quality Characteristics.

A Matrix of Influences (MoI) relates Properties and Quality Characteristics, as Table 1 shows. Properties and Quality Characteristics are organized in rows and columns; Properties (hierarchical in Features and Sub-Features) are listed in rows, and Quality 
Table 1 MoI (Matrix of Influences) to indicate association links between sub-features and quality subcharacteristics

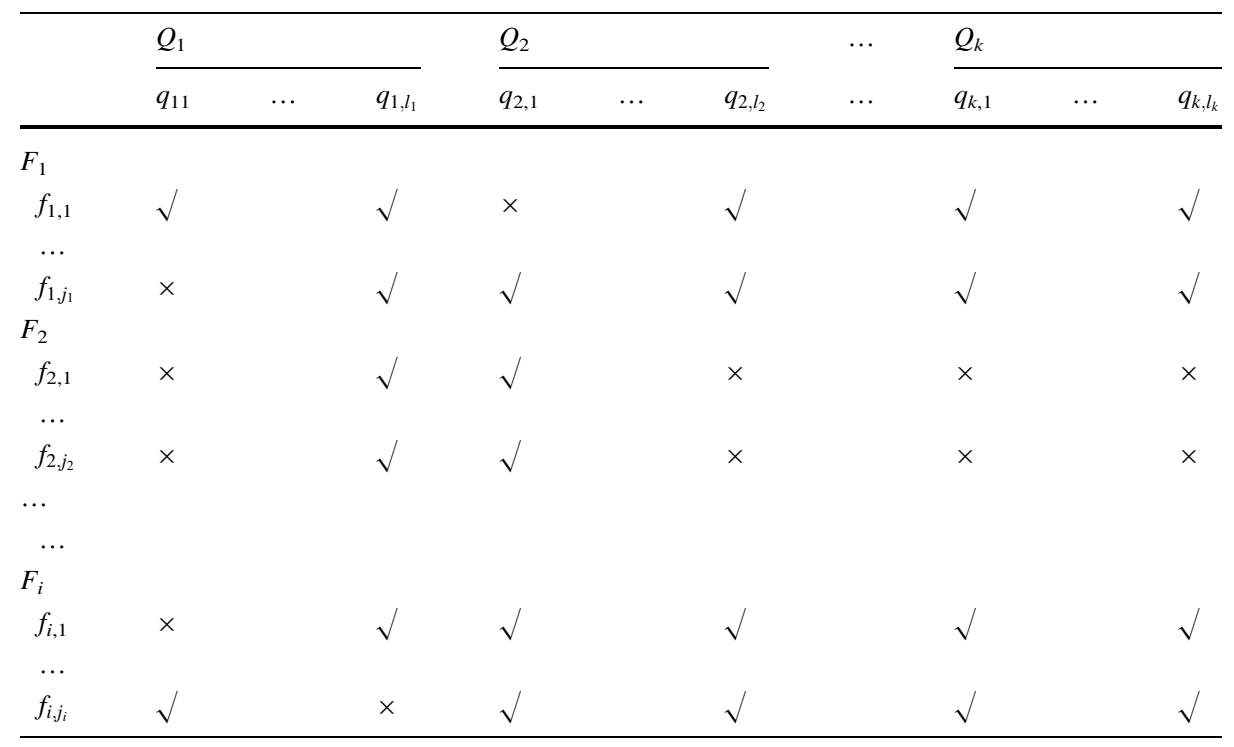

Characteristics (hierarchical in Quality Characteristics and Sub-Characteristics) are represented in columns. In the MoI, the Sub-Features value is calculated by means of the Checklists containing Properties (hierarchical in Features and Sub-Features) that are used to obtain the methodology value.

A qualitative value can determine the degree of influence on each relation modeled by a cell. In this case, the degree of influence is an association link between Sub-Features and Sub-Characteristics, regardless of the degree of importance. Thus, the MoI represents the degree of influence of each Sub-Feature on each Quality Sub-Characteristic. This is a qualitative value that has to be transformed into a quantitative value. For example, two value scales of the influence degree can only be defined as Influence $(\sqrt{ })$ or Not Influence $(\times)$.

\subsection{A quality model for applying e-SCM}

We have changed the matrix elements representation and have adapted the elements and relationship of our quality metamodel in order to prepare our Quality Metamodel (presented in Sect. 4.1) for the necessary implementation of e-SCM to manage offshore outsourcing quality between clients and providers. Now, Quality Characteristics represent the Number of Capability Level in e-SCM, Sub-Quality Characteristics represent the Name of Capability Level in e-SCM, Feature represents the Life-Cycle PhaseCapability Area in e-SCM, Sub-Feature represents the Procedure in e-SCM, and Property represents the Activity of e-SCM procedures. Now, Quality Characteristics relationship is $1 \ldots 1$ because each capability level has a unique name. Finally, Fig. 3 confirms the adaptation of our quality metamodel to e-SCM.

A MoI is directly built, after defining the quality metamodel for e-SCM. Table 2 illustrates the relationship between Capability Levels (columns) and Procedures or Models 


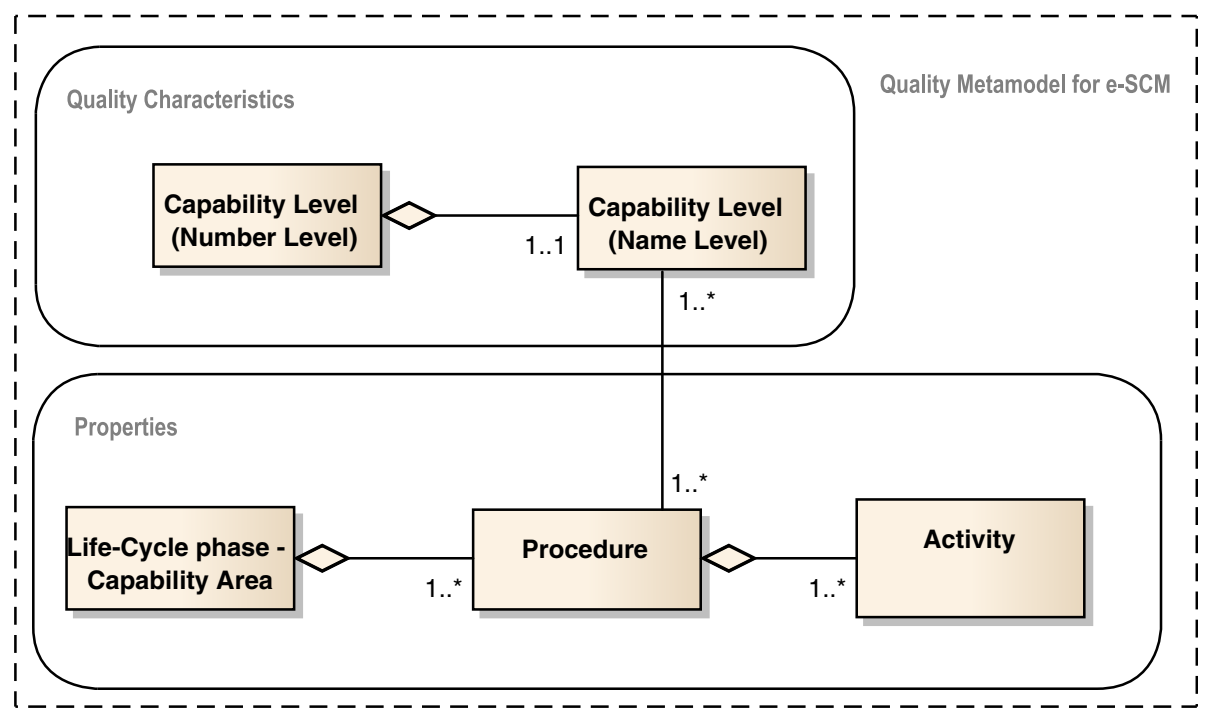

Fig. 3 Quality metamodel for e-SCM

Table 2 Adapted MoI (Matrix of Influences) to implement e-SCM models

\begin{tabular}{|c|c|c|c|c|c|}
\hline & $\begin{array}{l}\text { Capability } \\
\text { level } 1 \\
\text { Description }\end{array}$ & $\begin{array}{l}\text { Capability } \\
\text { level } 2 \\
\text { Description }\end{array}$ & $\begin{array}{l}\text { Capability } \\
\text { level } 3 \\
\text { Description }\end{array}$ & $\begin{array}{l}\text { Capability } \\
\text { level } 4 \\
\text { Description }\end{array}$ & $\begin{array}{l}\text { Capability } \\
\text { level } 5 \\
\text { Description }\end{array}$ \\
\hline \multicolumn{6}{|c|}{ Life-cycle Phase-Capability Area } \\
\hline $\begin{array}{l}\text { Model } \\
\ldots\end{array}$ & $\sqrt{ }$ & $x$ & $x$ & $\times$ & $\times$ \\
\hline $\begin{array}{c}\text { Model } \\
\text { Life-cycl }\end{array}$ & $\begin{array}{l}\sqrt{ } \\
\text { se-Capabilit }\end{array}$ & $\sqrt{ }$ & $\times$ & $\times$ & $x$ \\
\hline $\begin{array}{l}\text { Model } \\
\ldots\end{array}$ & $\sqrt{ }$ & $\sqrt{ }$ & $\times$ & $\times$ & $\times$ \\
\hline $\begin{array}{l}\text { Model } \\
\ldots \\
\ldots\end{array}$ & $\sqrt{ }$ & $\sqrt{ }$ & $\sqrt{ }$ & $\times$ & $\times$ \\
\hline \multicolumn{6}{|c|}{ Life-cycle Phase-Capability Area } \\
\hline $\begin{array}{l}\text { Model } \\
\ldots\end{array}$ & $\sqrt{ }$ & $\sqrt{ }$ & $\sqrt{ }$ & $\sqrt{ }$ & $\times$ \\
\hline Model & $\sqrt{ }$ & $\sqrt{ }$ & $\sqrt{ }$ & $\sqrt{ }$ & $\sqrt{ }$ \\
\hline
\end{tabular}

of each Life-Cycle Phase-Capability Area in e-SCM (rows). Relationships in MoI are represented by two symbols: $\sqrt{ }$ (Influence) and $\times$ (Not Influence).

Once the quality metamodel for e-SCM is defined, we can already design two models for e-SCM; the first one deals with the implementation of e-SCM-CL and the second one with the implementation of e-SCM-SP. However, we will only show the MoI for the Initiation Phase and Capability Levels of the e-SCM-CL model, not to overextend this paper. 
Then, Table 4 offers the MoI for the Initiation Phase and Capability Levels of the e-SCM-CL model, and Table 3 shows the Properties for SPE03 procedures (Select Candidate service providers of the e-SCM-CL model).

E-SCM-SP is designed to complement existing quality models so that service providers can capitalize on their previous improvement efforts. A series of documents comparing e-SCM-SP with other models and standards are developed. Each of the models is distributed along three dimensions: Sourcing Life Cycle, Capability Area and Capability Level.

Most quality models just focus on designing and delivering capabilities, but e-SCMSP's Sourcing Life Cycle not only includes delivery, but also initiation and completion of the contract. The two phases are often the most critical ones to successful sourcing relationships. The Sourcing Life Cycle also includes Overall Practices.

Capability Areas provide logical groupings of Practices to help users better remember and intellectually manage the content of the Model. Service providers can then build or demonstrate skills in a particular critical-sourcing function. The ten Capability Areas are as follows: Knowledge Management, People Management, Performance Management, Relationship Management, Technology Management, Threat Management, Service Transfer, Contracting, Service Design and Deployment, and Service Delivery.

The five e-SCM-SP's Capability Levels point out the level of an organization's capability. Level 1 specifies that the organization is providing a service. A Level 2 organization has procedures in place to allow meeting its clients' requirements consistently. At Level 3, an organization can manage its performance regularly across engagements. Level 4 requires an organization to be able to add value to its services through innovation. Service providers at Level 5 have proven that they can sustain excellence over a period of at least 2 years.

\subsection{A proposed framework to manage quality}

In this section, we propose a framework to manage Cloud Computing service quality that uses both quality models. We know that ISO 9000 includes eight quality management principles, on which to base an efficient, effective and adaptable quality management system. They are applicable throughout industry, commerce and service sectors:

- Customer focus: An effective QMS must guarantee that the organization has a strong Customer Focus. Customers' needs and expectations must be determined and transformed into product requirements.

- Leadership: Top management have to demonstrate Leadership, by providing unity of purpose through an appropriate quality policy, ensuring that measurable objectives are established and demonstrating that they are fully committed to developing, sustaining and improving the QMS.

- Involving people: Managers must make sure that people is involved in the organization at all levels. This entails ensuring that they are aware of the importance of meeting customers' requirements and the responsibilities it involves, and people are competent on the basis of appropriate training and experience.

- Process approach: An effective QMS must be a strategic tool designed to deliver business objectives, and must have, at its core, a Process Approach with each process transforming one or more inputs to create an output of value addressed to the customer. The key business processes may be supported by procedures and work instructions in those cases where it is deemed necessary to rigidly define what rules are to be followed 
Table 3 Properties for SPE03-Select Candidate service providers of the e-SCM-CL model

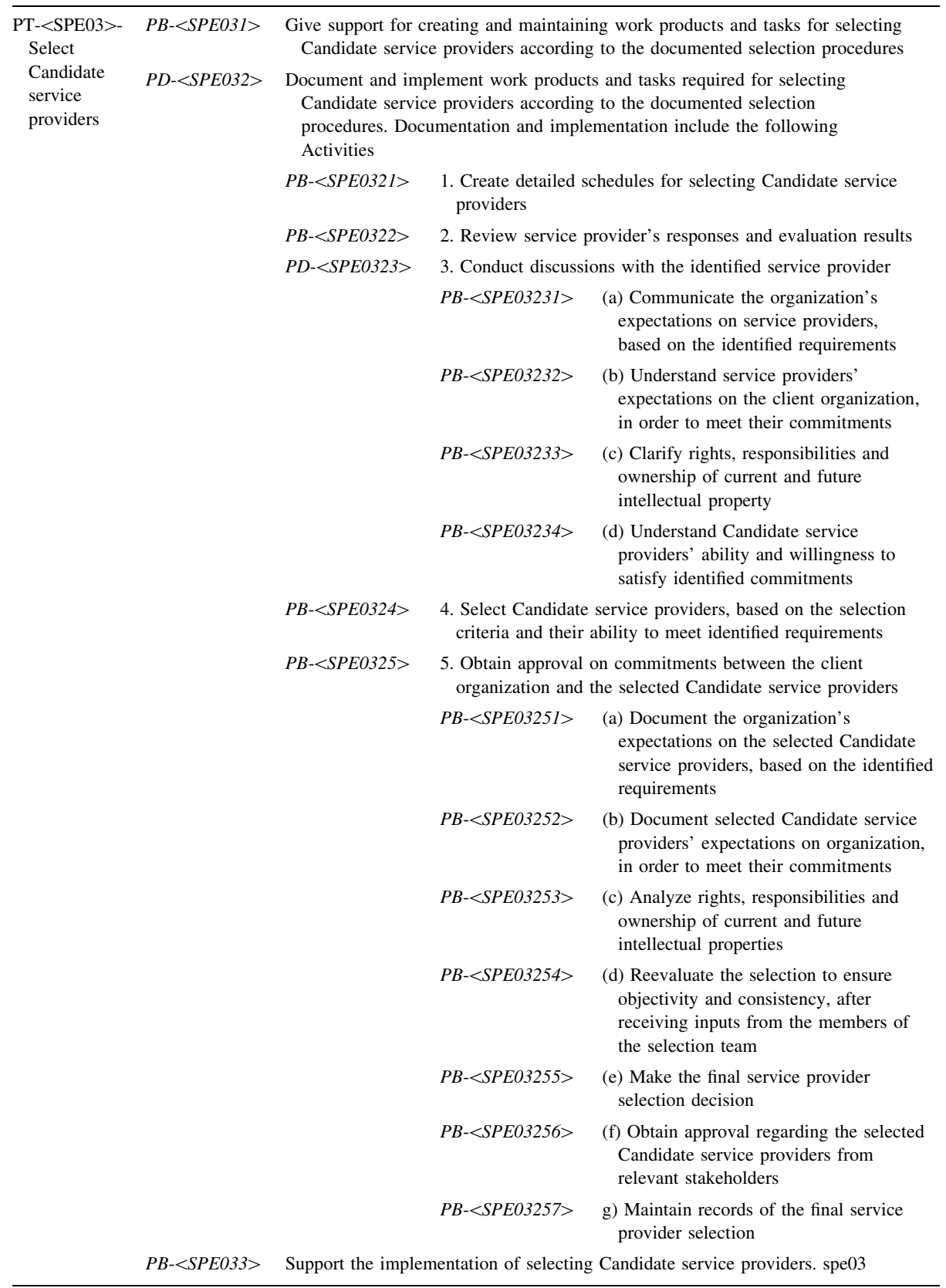

when undertaking a task. Most organizations will have core business processes that highlight those activities that directly add value to the product or service for the external customer, as well as support processes that are required to maintain the effectiveness of the core processes. 
Table 4 Matrix of Influences (MoI) for the Initiation Phase and Capability Levels of the e-SCM-CL model

$\begin{array}{lllll}\begin{array}{l}\text { Capability } \\ \text { level 1 }\end{array} & \begin{array}{l}\text { Capability } \\ \text { level 2 }\end{array} & \text { Capability level 3 } & \begin{array}{l}\text { Capability } \\ \text { level } 4\end{array} & \begin{array}{l}\text { Capability } \\ \text { level 5 }\end{array} \\ \text { sourcing } & \begin{array}{l}\text { Consistently } \\ \text { managing } \\ \text { sourcing }\end{array} & \begin{array}{l}\text { Managing } \\ \text { organizational } \\ \text { sourcing performance }\end{array} & \begin{array}{l}\text { Proactively } \\ \text { enhancing } \\ \text { value }\end{array} & \begin{array}{l}\text { Sustaining } \\ \text { excellence }\end{array} \\ & & & \end{array}$

\section{Initiation SPE-Service provider}

SPE01-

Communicate

Requirements

SPE02_Evaluate

Potential service

providers

SPE03-Select

Candidate service

providers

Initiation TFR - Service Transfer

TFR01-Service

Transition

TFR02_-Verify

Design

TFR03-Resources

Transferred Out

TFR04-Personnel

Transferred Out

TFR05-

Knowledge

Transferred Out

InitiationAGR - Sourcing Agreements

AGR01-

Negotiations

Guidelines

AGR02-Confirm

Existing

Conditions

AGR03-

Negotiations

AGR04-

Agreement Roles

AGR05-Define

SLAs and

Measures

AGR06-Create Agreements

AGR07-Amend

Agreements

Initiation PLN-Sourcing Planning

PLN01-Establish

Sourcing Project

PLN02-Service

Definition 
Table 4 continued

\begin{tabular}{|c|c|c|c|c|c|}
\hline & $\begin{array}{l}\text { Capability } \\
\text { level } 1 \\
\text { Performing } \\
\text { sourcing }\end{array}$ & $\begin{array}{l}\text { Capability } \\
\text { level } 2 \\
\text { Consistently } \\
\text { managing } \\
\text { sourcing }\end{array}$ & $\begin{array}{l}\text { Capability level } 3 \\
\text { Managing } \\
\text { organizational } \\
\text { sourcing } \\
\text { performance }\end{array}$ & $\begin{array}{l}\text { Capability } \\
\text { level } 4 \\
\text { Proactively } \\
\text { enhancing } \\
\text { value }\end{array}$ & $\begin{array}{l}\text { Capability } \\
\text { level } 5 \\
\text { Sustaining } \\
\text { excellence }\end{array}$ \\
\hline $\begin{array}{l}\text { PLN03-service } \\
\text { provider Selection } \\
\text { Procedures }\end{array}$ & $\sqrt{ }$ & $\sqrt{ }$ & $\times$ & $\times$ & $\times$ \\
\hline $\begin{array}{l}\text { PLN04_Evaluation } \\
\text { Criteria }\end{array}$ & $\sqrt{ }$ & $\sqrt{ }$ & $x$ & $\times$ & $x$ \\
\hline $\begin{array}{l}\text { PLN05_Prepare } \\
\text { Service } \\
\text { Requirements }\end{array}$ & $\sqrt{ }$ & $\sqrt{ }$ & $\times$ & $\times$ & $\times$ \\
\hline
\end{tabular}

- Systems approach: The understanding of these interrelationships among these processes demands that a Systems Approach to management be adopted. Processes must be thoroughly understood and managed so that available resources can be used in the most efficient way to ensure that the needs of all the stakeholders, customers, employees, shareholders and the community are met to get excellent Quality.

- Continual improvement: Customer satisfaction is a constantly moving entity depending on changes in technology and the market place, so an effective QMS must be in a state of continual improvement. For this purpose, attention must be paid to both the customer, through complaint analysis, opinion surveys and regular contacts, and processes, through measurement, monitoring and analysis of both process and product data.

- Factual decision-making: The continual improvement will result in Factual DecisionMaking.

- Mutually beneficial supplier relationships: Each organization constitutes itself just a link in the chain of a larger raw material process, and long-term needs of the community and the organization need to be Mutually Beneficial Supplier Relationships.

The framework we propose must ensure that two important requirements are met:

- Customers' requirements: Confidence in the ability of the organization to deliver the desired product and service consistently satisfying their needs and expectations.

- The organization's requirements: Both internally and externally, and at an optimum cost with efficient use of the available resources; material, staff, technology and information.

QuEF (Quality Evaluation Framework) (Domínguez-Mayo et al. 2012b) is a framework that was initially developed to manage Model-Driven Web Development methodologies quality, but has been extended (it is based on ITILv3, but it focuses on a quality model instead of a service) to cover the quality management of other areas or domains like e-Health Systems or Cloud Computing. QuEF has been improved with several phases (Fig. 4): Strategy phase, Design phase, Transition phase, Operation phase and Quality Continual Improvement phase. Such phases have been defined together with processes and 
Fig. 4 Phases of QuEF

(Domínguez-Mayo et al. 2012b)

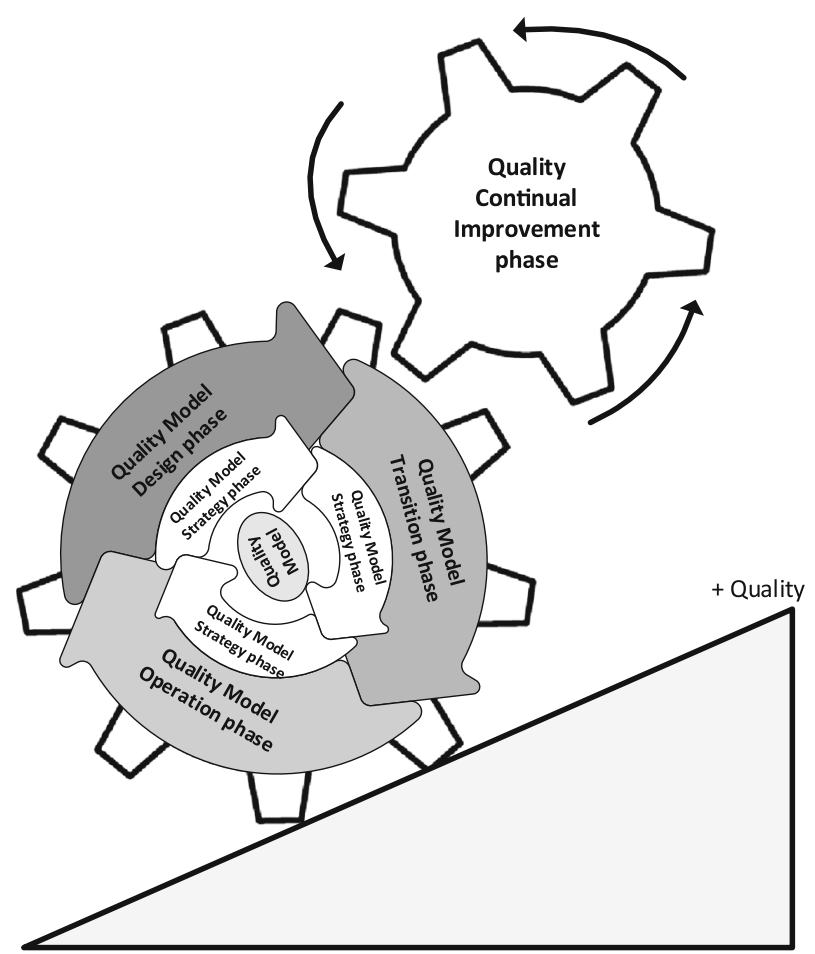

artifacts to cover a complete Quality Model lifecycle. The purpose of QuEF is to converge toward a continuous automatic quality improvement by means of generating Checklists and documentation as well as automatic evaluations and plans in order to control and improve quality and, in turn, automatically reduce effort and time.

- Quality Model Strategy: This phase is capital to the concept of Quality Model lifecycle, and its main objective is to transform quality management into a strategic active.

- Quality Model Design: This phase deals with providing guidance on the Quality Model design, processes and other aspects of the Quality Model final design management effort. Significantly, design in QuEF is understood to encompass all relevant elements to design the Quality Model.

- Quality Model Transition: This phase provides guidance on the Quality Model changes that have no influence on the Operation phase. This phase states how to manage changes on the Quality Model.

- Quality Model Operation: This phase provides guidance to perform the analysis, evaluation and planning on Cloud Computing quality continuous improvement. In this phase, the Quality Model is used to manage Cloud Computing quality.

- Quality Model Continual Improvement: This phase aims to align and realign the Quality Model with the real needs to cover and quality aspects to confirm with the 
approach stakeholder. The Quality Model can change in terms of the identification of news trends or because the technology has changed.

These requirements can only be truly met, if objective evidence is provided in the form of information and data, to support the system activities from the ultimate supplier to the ultimate customer.

The framework enables an organization to achieve the goals and objectives set out in its policy and strategy. It offers consistency and satisfaction in terms of methods, materials or equipment, and interacts with all activities in the organization, beginning with identifying customers' requirements and ending with their satisfaction at every transaction interface. QuEF can be implemented in all areas of activity, whether large or small businesses, manufacturing, service or public sector.

Using QuEF, which focuses on the Quality Model, the quality management of offshore outsourcing and Cloud Computing benefits the following points: set direction and meet customers expectations, improve process control, reduce wastage, lower cost, increase market share, facilitate training or involve staff, among others.

Adopting QuEF needs to be an organization's strategic decision, and it depends on varying needs, objectives, products/services provided, processes employed and the size and structure of the organization. QuEF must ensure that products/services conform customers' needs and expectations as well as the organization's objectives. As ISO recommends, issues to be considered when setting up QuEF include Design, Build, Control, Deployment, Measurement, Review and Improvement.

Taking each of these in turn:

- Design and Build includes the structure of the quality management system, process and implementation. The design must be led by senior managers to suit the organization's needs, and this is ideally executed by means of a framework to direct the thinking. The design of the framework should come from determining the organization's core processes and well-defined goals and strategies, and should be linked to the needs of one or more stakeholders. The process of designing and building the framework must also be clear, with the quality function playing a key role, but buy-in and involvement in the system must also come from all other functions.

- Deployment and implementation are best achieved using process packages, where each core process is broken down into sub-processes and described by a combination of documentation, education, training, tools, systems and metrics.

- Control of the framework will depend on the size and complexity of the organization. ISO is a site-based system, and local audits and reviews are essential, even if these are supplemented by central reviews. Local control, wherever possible, is effective, and good practice cases are found where key stakeholders are documented on the process and the process owner is allowed to control all of the process. Ideally, process owners/ operators are involved in writing procedures.

- Measurement is carried out to determine the effectiveness and efficiency of each process toward attaining objectives. It should include the contribution of the framework to the organization's goals. This could be achieved by measuring the following: policy definition completeness, coverage of business, reflection on policies, deployment, usage, whether staff find the framework helpful to their work, speed of change of the framework and relevance of framework architecture to the job in hand.

A form of scorecard deployed through the organization down to the individual objective level can be utilized, and setting targets at all levels is essential. 


\section{A tool support to apply e-SCM for clients and providers}

Every day we have new, complex and novel applications in the market that house different areas of interest. Therefore, the need arises for power tools to perform quality management effectively and efficiently. In this case, we need some way to apply the e-SCM model in a more efficient and simple way and above all, saving costs and time.

This section shows a tool support for the framework, explained in the previous section, to apply this model for Services and providers.

IWT2 research group (Web Engineering \& Early Testing) is developing QuEF-TS that means, a set of software factories and Web applications generated by these factories that support QuEF. The idea is to automate all processes and artifacts QuEF defines for each phase.

QuEF-TS is divided into different factories for each phase. Thus, each factory can generate all software tools or Web applications in terms of the Quality Model specified. Then, factories containing QuEF-TS can produce the following Web applications or tool support for each phase of QuEF:

- QuEF-S Web application: It is generated by QuEF-S Factory, and it is the tool that supports the Quality Model Strategy phase. (It is currently being developed)

- QuEF-D Web application: It is generated by QuEF-D Factory, and it is the tool that supports the Quality Model Design phase. (It has not been developed yet)

- QuEF-T Web application: It is generated by QuEF-T Factory, and it is the tool that supports the Quality Model Transition phase. (It has not been developed yet)

- QuEF-O Web application: It is generated by QuEF-O Factory, and it is the tool that supports the Quality Model Operation phase. It has already been developed, and this Web application can generate specific checklists and all the necessary elements based on the Quality Model to analyze, control and evaluate it.

- QuEF-QCI Web application: It is generated by QuEF-QCI Factory, and it is the tool that supports the Quality Continual Improvement in quality management. (It has not been developed yet)

In our case, we provide an Enterprise Architect modeling environment with UML 2.2, which is given by model constructions. We use Microsoft Visual Studio 2010 for code development, which is an IDE (Integrated Development Environment) for Windows operating systems. The selected language is C\#, which is an object-oriented programming language developed and standardized by Microsoft as part of the platform. Finally, we make use of Microsoft SQL Server, which is a system for managing databases produced by Microsoft and focused on the relational model.

Quality management is performed in the Operation phase. QuEF-O Factory and QuEF$\mathrm{O}$ Web application have already been developed completely. In these lines, within the transferring projects context of IWT2 research group, we have realized that there is a gap in the market in terms of deciding on the most suitable software product for organizations which, at the same time, enforces the quality management of these software products at organizations. In addition, when working in transferring projects to organizations, we have found similar problems and drawbacks in all of them.

The THOT project is a transfer project carried out in collaboration with the public government of Andalucía (Junta de Andalucía) in Spain. It has two main objectives; on the one hand, to obtain a detailed analysis and evaluation of Document Management Systems (DMS) applied to contracting records for infrastructure projects of transports and services; on the other hand, to find out and define an innovative solution that may improve 
procedural records management. Currently, there are several solutions for this type of systems in the market, although we have selected the most appropriate one in relation to the scope of the project. Thus, QuEF-O Factory and QuEF-O Web application have been used to obtain the detailed analysis and evaluation of different DMS alternatives.

ADAPTA is another project that is using this tool. It is an Interconnecta Project, leaded by INDRA, which is developed along with a consortium of companies. Among these companies, Wellness Telecom has outsourced our research group to be provided with a detailed analysis and evaluation of tools for capturing and defining requirements in Web environments. Then, we meet again the same problem; therefore, we have to analyze and evaluate these tools in order to select the most appropriate one for the project.

Another example that states the relevance of QuEF-O Factory and QuEF-O Web Application for our research group concerns the implementation of standards. We have noticed that organizations with which we usually work always need to implement standards and best practices to be more competitive in the market. Thus, this is other case that leads us to decide what standard and best practice is more appropriate to the nature of the organization, by means of justifying the quality associated with their implementation and helping them implement standards. It similarly happens in other contexts such as e-Health, e-Government or e-Learning, among others.

Implementation of standards is the context where we have found the necessity to align the service capability that our research group provides to our clients simultaneously with the service capability that our research group receives from our providers, in order to ensure the quality of this service. Consequently, this tool has been applied to the e-SCM model. Furthermore, we describe this tool and its uses in the following paragraphs.

Activity diagrams are used to describe the business and operational step-by-step workflows of components within the system. In Fig. 5, we can see the overall flow of control between users (not necessarily registered users) and the system administrator. Activity diagrams are constructed from a limited number of shapes, connected with arrows. The most important shape types are as follows: rounded rectangles, representing activities; diamonds, representing decisions; a black circle, representing the start (initial state) of the workflow; and an encircled black circle, representing the end (final state). This activity diagram represents the process to manage quality by means of these applications. First of all, the administrator creates the Quality Model and, later on, the users validate it. If they approve the quality model, the administrator can generate the QuEF-O Web application. The first thing the administrator must cope with is editing weights and MoI values. Then, users must validate such weights and MoI values depending on their project contexts and finally, quality can be managed.

Figure 6 shows the use case diagrams defining the different roles involved in QuEF-O Factory and QuEF-O Web application generated by the factory, respectively. This use case shows the functionalities of each user role for QuEF-O Factory and QuEF-O Web application. In QuEF-O Factory, the Administrator is the person in charge of creating and editing the quality model and generating QuEF-O Web application. However, as regards QuEF-O Web application, the user can only evaluate Properties and Quality Characteristics while the registered user can $\log$ in and out as well as complete and edit checklists. In contrast, the administrator can perform all these functionalities and edit weights and MoI values.

With regard to the design and used technology, it must be highlighted that the system architecture is designed according to design patterns to carry out the implementation. One of the main buildings is the standard Web Forms model used for the generation of the Web. Web Forms is a programming model whose main feature is the level of abstraction and 


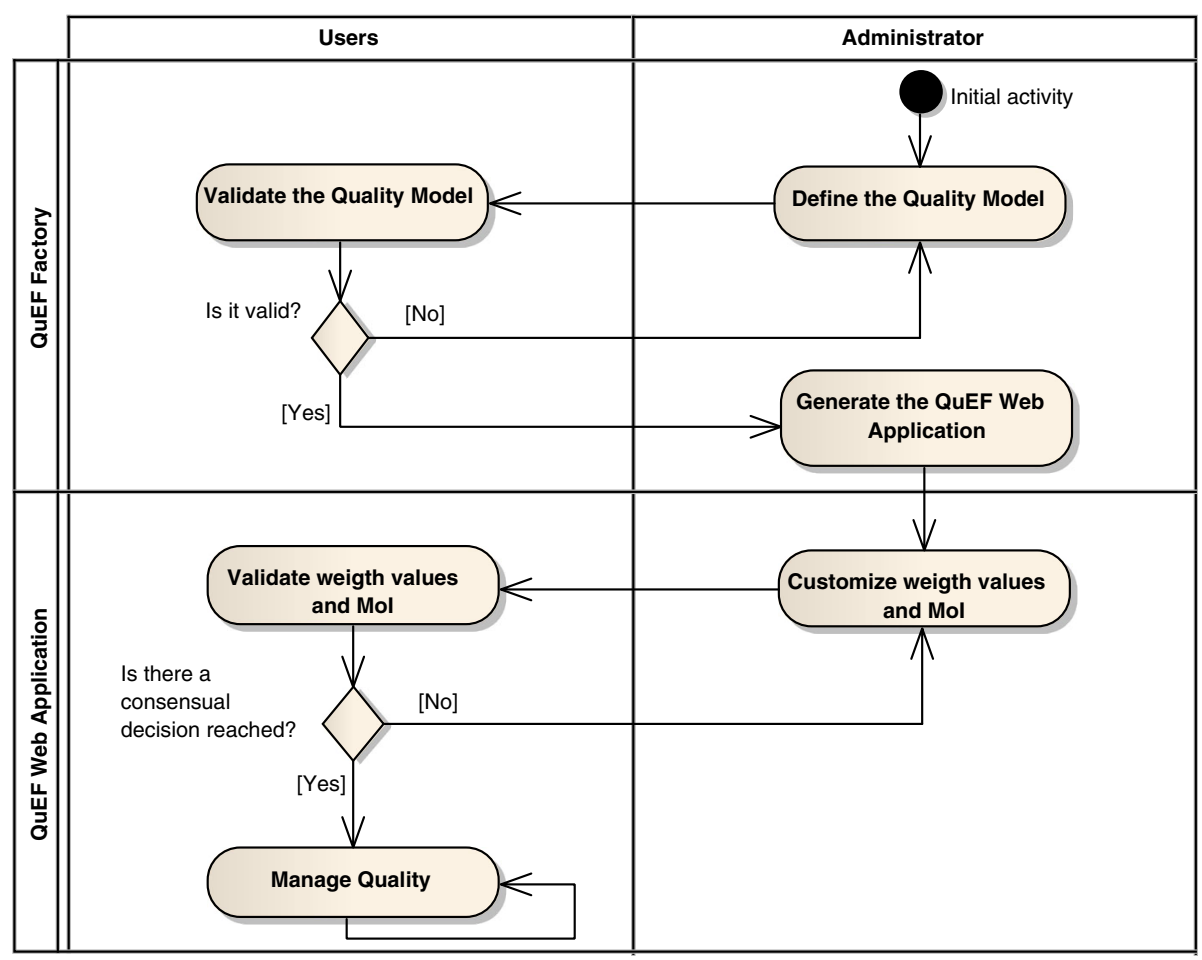

Fig. 5 Activity diagram for the use of the tool support

encapsulation it provides, although this is extremely versatile. Web Forms is a technology on which Microsoft keeps on investing heavily. However, ASP.NET 4.0 is one of the pillars as it introduces new features and improvements that correct many of those historically considered weaknesses. As known, NET Framework was for many years the only Web Forms programming model available.

At birth, Web Forms introduced significant developments with respect to other Web development technologies such as ASP, PHP or JSP. The split between server code and HTML markup was one of the most relevant developments. The typical structure of a Web Forms page consists of one side of a *. aspx which defines the structure and adds HTML server controls declaratively on the page (server controls will be further explained below). Besides, the source code behind file, either *. aspx.cs or *. aspx.vb, appears depending on the programming language to deploy the server code page. Subsequently, both files are compiled into assemblies containing the server code that generates the HTML delivered to run the page.

QuEF-O Factory generates QuEF-O Web application using the developed plugin for Enterprise Architect. As we have already done along previous sections and due to the particularities of this project, we have to divide our study in two parts; the former dealing with the factory and a latter with the Web generation. The following figures represent the class diagram of the QuEF-O Factory.

Figure 7 shows the QuEF-TS generator application (it includes QuEF-O Factory). This application lets the user select the Directory to produce the Web Application code and the 
QuEF phases or tools to be generated. This interface is the one we visualize before creating the Web application. There are many options for setting up the system, but for now, only one of them is available (the generation of QuEF-O Web application).

Finally, the Web application with the selected tools is generated. Figure 8 provides an example of the QuEF-O Web application produced in terms of the Quality Model. In this example, all checklists are designed in order to identify which Capability Area and Lifecycle Phase are implemented.
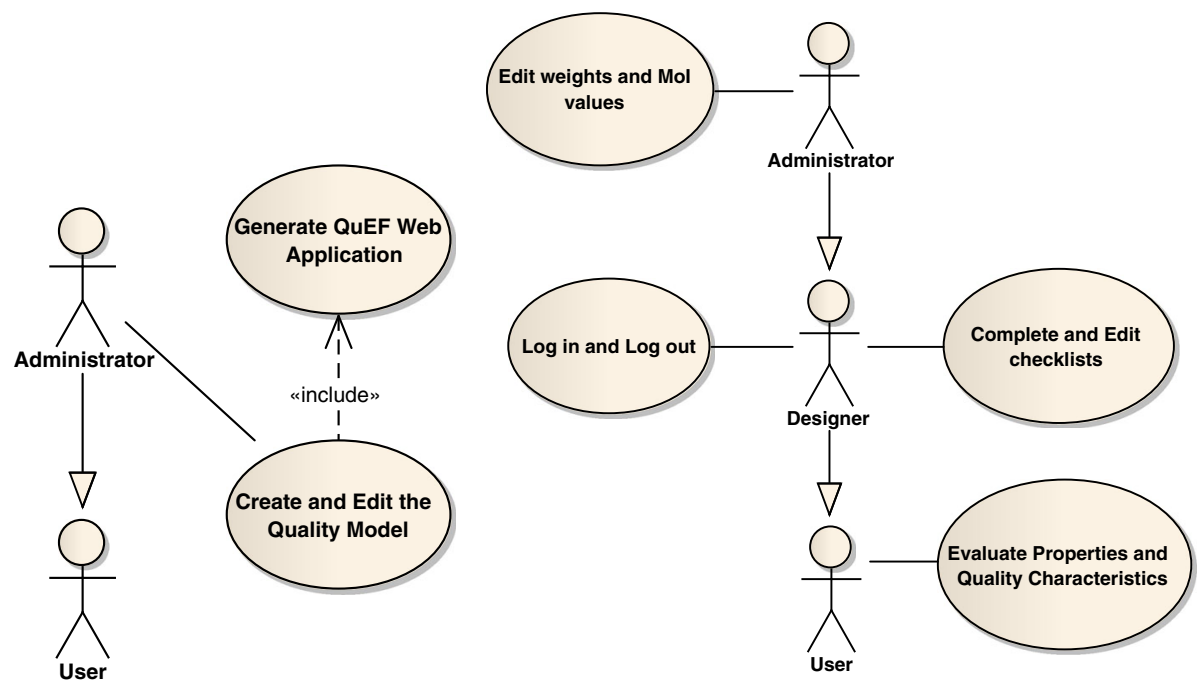

Fig. 6 Use cases for the QuEF-O Factory and QuEF-O Web application

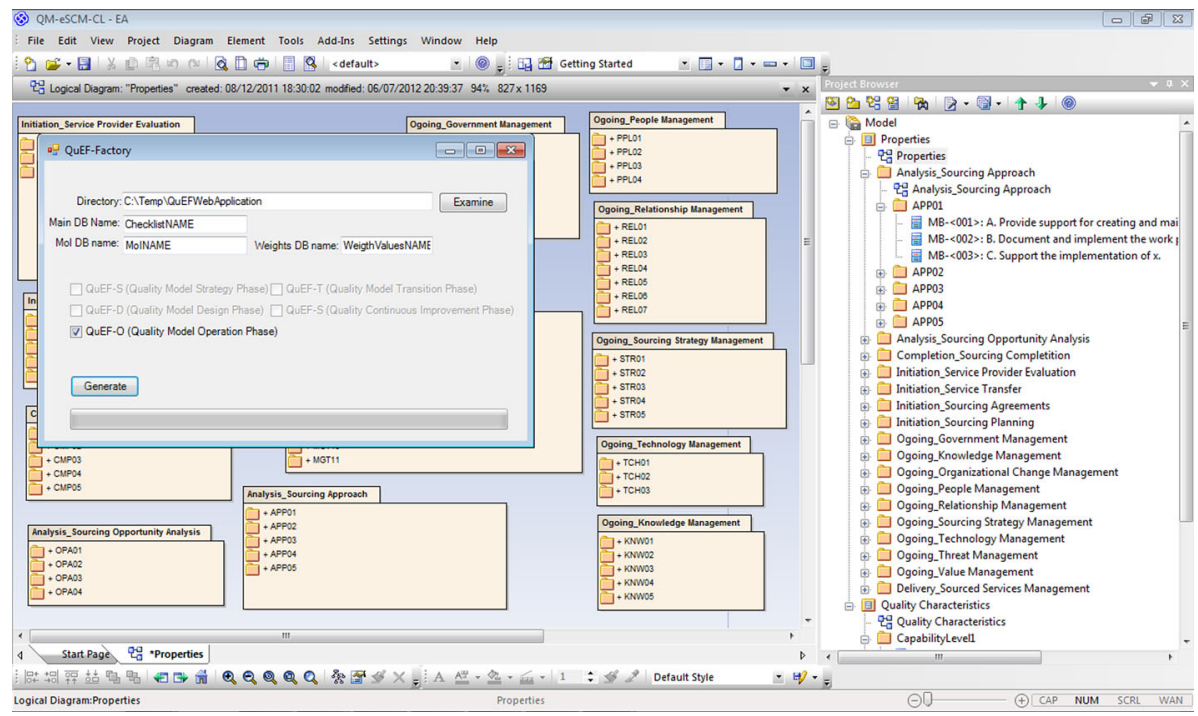

Fig. 7 The Quality Model defined in Enterprise Architect 


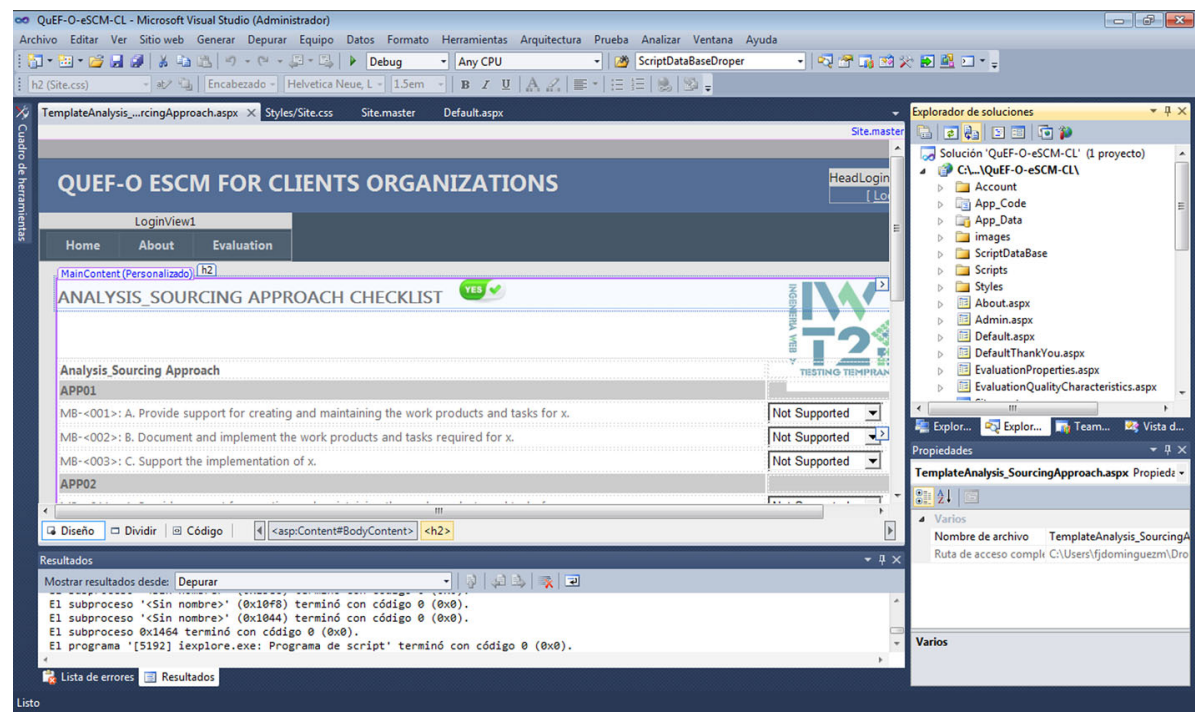

Fig. 8 QuEF-O Factory generates code

We remember that the idea is to automate the analysis, evaluation and plan of Cloud Computing service quality continual improvement for the Quality Model.

The default page on QuEF-O Web application shows the log in main page, where users can log in and access the Web application. Depending on their roles in the Web application (user, registered user or administrator), the user can access different functionalities as we have seen in the analysis section.

Once registered users have accessed to QuEF-O Web application, they can fill in checklists selected from the menu elements, as shown in Fig. 9. These checklists are stored and can be updated by registered users.

There is a set of checklists for each registered user. Unregistered users can just visualize the value of these checklists, but they cannot edit them on the evaluation menu option.

For the analyses, there are three different options for registered users and the administrator, who is the only one that can edit all these values. Registered users can only examine values for MoI, weight values for Properties and weight values for Quality Characteristics. In the implementation, the checklist menu has been separated from the analysis menu, so that it can be more accessible to users.

As previously mentioned, the administrator is the only one that can edit value in these interfaces. Consequently, the showed interfaces correspond to the administrator role.

Finally, we can evaluate Properties and Quality Characteristics as shown in the next figures. Figure 10 represents the capability level of a client in terms of the implemented Sourcing Life Cycle and Capability Area. The values can also be compared with other registered clients values. Thus, we cannot only compare their capability level, but also their Sourcing Life Cycle and Capability Area. Figure 11 shows the capability level of a provider regarding the implemented Sourcing Life Cycle and Capability Area. In this sample, the application of results would conclude that both client and provider are aligned to work together. 


\section{QuEF-O Escm FOR CLIENTS ORganizations}

\section{\begin{tabular}{|l|c|c|c|c|}
\hline Home & Checklists & Analyses & Evaluations & About \\
\hline
\end{tabular}}

Properties

Analysis Sourcing Approach Checklist $\varpi$.

Completion Sourcing Completition Checklist 6 .

Initiation Service Provider Evaluation Checklist

Analysis Sourcing Opportunity Analysis Checklist E.

Initiation Service Transfer Checklist -

Initiation Sourcing Agreements Checklist $\sigma$.

Initiation Sourcing Planning Checklist E.

Ogoing Government Management Checklist $\sigma$.

Ogoing Government Management Checklist

Ogoing Organizational Change Management Checklist $\sigma$.

Ogoing People Management Checklist

Ogoing Relationship Management Checklist $\sigma$.

Ogoing Sourcing Strategy Management Checklist E.

Ogoing Technology Management Checklist -

Ogoing Threat Management Checklist -

Ogoing Value Management Checklist

Delivery Sourced Services Management Checklist - .

[ Log Out ]

Fig. 9 Checklists are used to analyze the Sourcing Life Cycle and the Capability Area for client Organizations and service providers

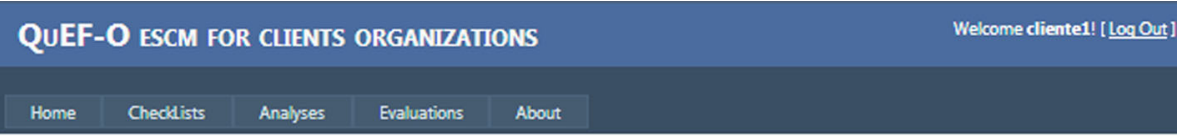

Evaluations of Values from Qualtry Characteristics

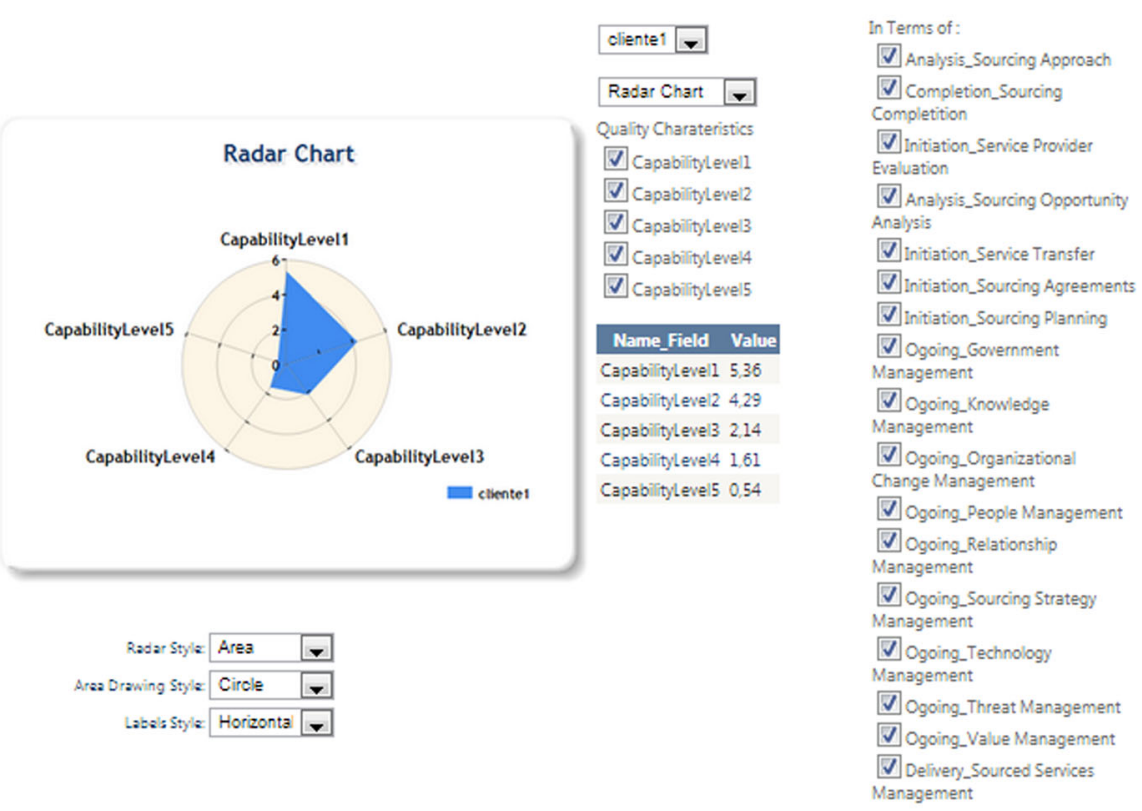

Fig. 10 Capability level of a client organization 


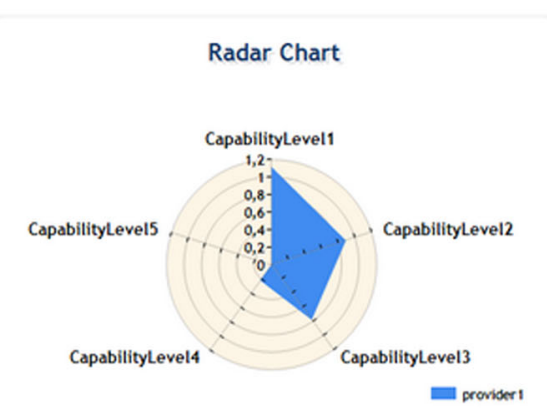

provider 1 provider1 $\rightarrow$

Radar Chart

Quality Charateristics

$\square$ Capabilitylevell

D Capabilitylevel2

V Capabiiltylevel3

$\nabla$ Capabilitylevel4

$\square$ Capabilitylevel5

Name_Field Value

Capabilitylevel1 1,12

Capabilitylevel2 0,89

Capabilitylevel3 0,78

Capabilitylevel 40.22

Capabilitylevel5 0

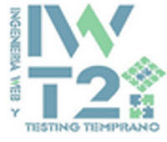

In Terms of:

$\square$ Initiation_Contracting

$\nabla$ Ongoing_Knowledge

Management

VInitiation_Service Design and

Deployment

$\square$ Initiation_Service Transfer

[ Ongoing_People Management

$\square$ Ongoing_Performance

Management

\ Ongoing_Relationship

Management

$\square$ Ongoing_Technology

Management

$\square$ Ongoing_Threat Management

$\square$ Delivery_Senvice Delivery

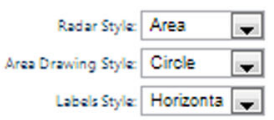

Submit

Fig. 11 Capability levels of a service provider

\section{Conclusions and future work}

This paper proposes a framework for managing Cloud Computing service quality between clients and providers efficiently and effectively. For this purpose, a SLR was performed in order to deal with identified gaps in the quality management of offshore outsourcing and Cloud Computing and determine the most analyzed offshore outsourcing and Cloud Computing studies. The aim was to identify whether a framework and a tool support exist for the quality management of offshore outsourcing and Cloud Computing reducing costs, effort and time. This study has concluded that there are no found works focused on frameworks that can ensure the quality management in Cloud Computing service between clients and providers.

In consequence, we propose a Quality Model metamodel, which is an adaptation and simplification of ISO/IEC 15939 (ISO/IEC 15939:2007 2012), to make the model instantiation more flexible and practical. Nevertheless, the QuEF framework allows establishing appropriate strategies to facilitate the implementation of Cloud Computing as an offshore outsourcing between clients and providers. The objective is to align them in order to work with ICT as the general business in the Cloud that uses these services through a capability model. The Sourcing Capability Maturity Model for service (e-SCM), which is a capability model for offshore outsourcing between clients and providers to achieve the required quality of service and develop an effective working relationship 
between them, has been used to solve this problem. Besides, we recommend a framework to handle quality when applying the e-SCM model between both client and providers.

The framework offers a set of phases and tools to manage quality efficiently and effectively. Concerning tool support, IWT2 research group is developing QuEF-TS that means, a set of software factories and Web applications generated by these factories that support QuEF. The idea is to systematize all processes and artifacts defined on QuEF for each phase.

QuEF supporting tools enable to manage Cloud Computing quality between clients and providers by means of e-SCM. The tool support has been shown in the paper in order to apply the e-SCM model in a more efficient and simplified way and mainly saving costs and time for clients and providers. This tool allows them to evaluate the current state of each Capability Area and Life-Cycle Phase as well as the present state of their capability levels. Being aware of their current state is capital for them, as they need to work together to ensure success.

The framework and the tool support can also be applied to other contexts and domains. Therefore, we believe that we can provide knowledge and improve the quality of processes in the Health context. Therefore, as future work, we will expand and implement our quality metamodel to the Health area with the intention of improving medical processes and patients' experience.

Our quality model can also be adapted to assess not only capability models and standards, but also any process or product. As an illustrative example, it is worth mentioning that QuEF is now being applied to the THOT Project (funded by the Feder of European Union), which is the current work that IWT2 research group is developing. In the THOT project, we are analyzing and evaluating quality in different Document Management Software systems for the public administration.

Acknowledgments This research has been supported by the MeGUS (Mecanismos Guiados en etapas tempranas para la Mejora de Software), Ministerio de Ciencia e Innovación (TIN2013-46928-C3-3-R), by the NDTQ-Framework project (TIC-5789) of Junta de Andalucía (Spain) and by the FEDER of European Union for financial support via project "THOT. Proyecto de innovación de la gestión documental aplicada a expedientes de contratación de servicios y obras de infraestructuras de transporte" of the "Programa Operativo FEDER de Andalucía 2007-2013". We also thank all the Staff and Researches of the Regional Government of Andalucía Agency of Public Work for their dedication and professionalism.

\section{References}

Alvi, F. A., Choudary, B. S., Jaferry, N., \& Pathan, E. (2011). A review on cloud computing security issues \& challenges. http://www.pbltt2011.mfu.ac.th/download/full_paper/C3_Fizza\%20Abbas-TTPBL-Full\% 20paper_A\%20Review\%20on\%20cloud\%20computing\%20security $\% 20$ issues $\% 20$ and $\% 20$ challenges. pdf.

Brinkkemper, S., \& Jansen, S. (2012). Collaboration in outsourcing. Palgrave Macmillan, ISBN: 978-0-23034770-0.

Buyya, R., Shin Yeo, C., Venugopal, S., Broberg, J., \& Brandic, I. (2009). Cloud computing and emerging IT platforms: Vision, hype, and reality for delivering computing as the 5th utility. Future Generation Computer Systems, 25(6), 599-616. doi: 10.1016/j.future.2008.12.001, ISSN 0167-739X.

CMMI Official site: http://www.sei.cmu.edu/cmmi/. Carnegie Mellon University Software Engineering Institute. Retrieved July 2012.

Domínguez-Mayo, F. J., Escalona, M. J., Mejías, M., Ross, M., \& Staples, G. (2012a). Quality evaluation for model-driven web engineering methodologies. Information Software Technology, 54(11), 1265-1282.

Domínguez-Mayo, F. J., Escalona, M. J., Mejías, M., Ross, M., \& Staples, G. (2012b). A quality management based on the quality model life cycle. Computer Standards \& Interfaces, 34(4), 396-412. 
Dudin, E. B., \& Smetanin, Y. G. (2011). A review of cloud computing. Scientific and Technical Information Processing, 38(4), 280-284.

Haider, W., \& Wahab, A. (2011). A review on Cloud Computing Architectures and Applications. Computer Engineering and Intelligent Systems, 2(4), 206-210.

Hu, F., Qiu, M., Li, J., Grant, T., Tylor, D., McCaleb, S., et al. (2011). A review on cloud computing: Design challenges in architecture and security. Journal of Computing and Information Technology, 19(1), 25-55.

Hughes, G. (2011). Research, design and development review of the Cloud Computing Management System (CCMS). In International Conference for Internet Technology and Secured Transactions (ICITST) (pp. 128-131).

Hughes, G., Al-Jumeily, D., Hussain, A. J. (2011). Research, design and development review of the Cloud Computing Management System (CCMS). In International conference for internet technology and secured transactions, ICITST 2011, art. no. 6148365 (pp. 128-131).

ISO/IEC 15939:2007 Systems and software engineering-measurement process. Retrieved March 2012, from http://www.iso.org.

ITIL Official site: http://www.itil-officialsite.com/ Retrieved July 2012.

ITSqc Official site: http://www.itsqc.org Retrieved July 2012.

Kitchenham, B. A., \& Charters, S. (2007). Guidelines for performing systematic literature reviews in software engineering no. EBSE-2007-01.

Lian-xiang, H. U. (2011). Review of researches on Cloud Computing Application in Domestic Libraries. Journal of Library and Information Sciences in Agriculture.

Ma, S. (2012). A review on cloud computing development. Journal of Networks, 7(2), 305-310.

Marta, F. C., Correia, A. M. R., \& Neves, F. T., (2011). Supporting KMS through cloud computing: A scoping review. In Proceedings of the 6th Iberian conference on information systems and technologies, CISTI 2011, art. no. 5974347.

Monaco, A. (2012). A view inside the cloud. theinstitute.iee.org (IEEE). Retrieved August 21, 2012.

Nazareno, F., Kyung-Hee, L., \& Wan-Sup, C. (2010). Mining molecular interactions from scientific literature using cloud computing. In IEEE international conference on bioinformatics and biomedicine workshops (BIBMW) (pp. 864-865). doi: 10.1109/BIBMW.2010.5703948.

Rebollo, O., Mellado, D., \& Fernández-Medina, E. (2012). A systematic review of information security governance frameworks in the cloud computing environment. Journal of Universal Computer Science, 18(6), 798-815.

Roberts II, J. C., \& Al-Hamdani, W. (2011). Who can you trust in the cloud? A review of security issues within cloud computing. In Proceedings of the 2011 information security curriculum development conference, InfoSecCD'11 (pp. 15-19).

Samimi, P., \& Patel, A. (2011). Review of pricing models for grid \& cloud computing. In ISCI 2011-2011 IEEE.

Song, W., \& Su, X. (2011). Review of mobile cloud computing. In 2011 IEEE 3rd international conference on communication software and networks, ICCSN 2011, art. no. 6014374, (pp. 1-4).

TickITplus Official site: http://www.tickitplus.org/Information.aspx, Retrieved May 2012.

Timmermans, J., Ikonen, V., Stahl, B. C., \& Bozdag, E. (2010). The ethics of cloud computing: A conceptual review. In Proceedings-2nd IEEE international conference on cloud computing technology and science, CloudCom 2010, art. no. 5708509 (pp. 614-620).

Vats, K., Sharma, S., \& Rathee, A. (2012). A review of cloud computing and e-governance. International Journal of Advanced Research in Computer Science and Software Engineering, 2(2) (2012). http:// www.ijarcsse.com/docs/papers/february2012/volume_2_issue_2/V2I2074.pdf.

Wei, Z. (2010). An initial review of cloud computing services research development. In Multimedia information networking and security (MINES), 2010 international conference on (pp. 324-328). doi: 10.1109/MINES.2010.75.

Yang, H., \& Tate, M. (2009). Where are we at with cloud computing? A descriptive literature review. In 12th Australian conference on knowledge management and intelligent decision support, ACKMIDS 09 and 20th Australasian conference on information systems, ACIS 2009 (pp. 807-819).

Zhao, W. (2010). An initial review of cloud computing services research development. In Proceedings2010 2nd international conference on multimedia information networking and security, MINES 2010, art. no. 5670830 (pp. 324-328). 